\title{
(6) OPEN ACCESS \\ International comparisons of the consultation prevalence of musculoskeletal conditions using population-based healthcare data from England and Sweden
}

\author{
Kelvin P Jordan, ${ }^{1}$ Anna Jöud, ${ }^{2,3}$ Charlotte Bergknut, ${ }^{2,3}$ Peter Croft, ${ }^{1}$ \\ John J Edwards, ${ }^{1}$ George Peat, ${ }^{1}$ Ingemar F Petersson, ${ }^{2,3}$ Aleksandra Turkiewicz, ${ }^{2}$ \\ Ross Wilkie, ${ }^{1}$ Martin Englund ${ }^{2,3,4}$
}

\begin{abstract}
Handling editor Tore K Kvien
- Additional material is published online only. To view please visit the journal online (http://dx.doi.org/10.1136/ annrheumdis-2012-202634).

${ }^{1}$ Arthritis Research UK Primary Care Centre, Keele University, Keele, UK

${ }^{2}$ Department of Orthopedics, Clinical Sciences Lund, Lund University, Lund, Sweden ${ }^{3}$ Epi-centre Skåne, Skåne University Hospital, Lund, Sweden

${ }^{4}$ Clinical Epidemiology Research and Training Unit, Boston University School of Medicine, Boston,

Massachusetts, USA
\end{abstract}

\section{Correspondence to} Dr Kelvin P Jordan, Arthritis Research UK Primary Care Centre, Primary Care Sciences, Keele University, Keele, Staffs ST5 5BG, UK; k.p.jordan@ keele.ac.uk

$\mathrm{KPJ}$ and $\mathrm{AJ}$ are co-lead authors.

Received 7 September 2012 Revised 26 November 2012 Accepted 28 December 2012 Published Online First 23 January 2013

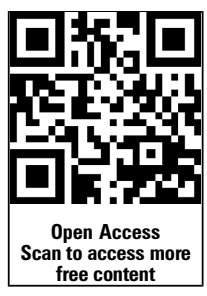

\begin{tabular}{|l|}
\hline To cite: Jordan KP, Jöud A, \\
Bergknut C, et al. Ann \\
Rheum Dis 2014;73: \\
212-218. \\
\hline
\end{tabular}

\section{ABSTRACT}

Objectives To assess the consultation prevalence of musculoskeletal (MSK) conditions as presented in different healthcare systems, and to determine the feasibility of comparing prevalence figures between nations.

Methods The settings were an English regional database (Consultations in Primary Care Archive (CiPCA)) and the Swedish Skåne County Health Care Register. Case definitions, data extraction and analysis procedures were harmonised. The number of people consulting per 10000 registered population in primary care, and in primary or secondary care, in the year 2010 (annual consultation prevalence) were determined for doctordiagnosed osteoarthritis (OA), rheumatoid arthritis (RA), low back pain, and spondyloarthritis including psoriatic arthritis and ankylosing spondylitis (AS). Seven-year period consultation prevalences were also determined.

Results Combining primary and secondary care, annual consultation prevalences of any MSK condition (2143 vs $1610 / 10000$ ) and low back pain (587 vs 294/10 000) were higher in England than in Sweden, but higher for RA, spondyloarthritis and psoriatic arthritis in Sweden. Annual primary care prevalence figures for OA (176 vs $196 / 10000$ ), RA (25 vs $26 / 10000$ ), spondyloarthritis (both $8 / 10000$ ) and psoriatic arthritis (5 vs 3/10 000) were similar between England and Sweden. AS was rarely recorded in Swedish primary care. These patterns were also observed for 7-year period consultation prevalences.

Conclusions A rigorous methodological approach allowed feasible comparison of MSK consultation prevalence between England and Sweden. Differences in prevalence of inflammatory and unspecific pain conditions may be partially explained by known variations in healthcare systems and recording practice. Routine healthcare data offers potential for investigating variations in occurrence and outcome of MSK conditions between nations.

\section{INTRODUCTION}

Musculoskeletal conditions are the dominant source of chronic pain worldwide, ${ }^{1}$ and the basis for the most common pain complaints presented to primary care. $^{2-4}$ Conditions such as low back pain (LPB) and osteoarthritis (OA) have a significant impact on individuals and healthcare systems. ${ }^{5}$ Compared with other morbidities, for instance, cancer and heart disease, there remain significant gaps in our understanding of the frequency and management of musculoskeletal (MSK) conditions and their variations between countries. Comparisons between countries would allow further exploration of the pathogenesis of MSK conditions and assessment of differences in healthcare.

Routinely collected electronic healthcare data provide a valuable source of information on trends and variation in the occurrence, determinants, consequences and management of health problems. With falling response rates and under-representation of segments of the population in surveys, healthcare databases may provide the most valid basis for quantifying occurrence of morbidity. ${ }^{6}$ Yet, comparing estimates on healthcare use even within the same country can be difficult, ${ }^{78}$ and there are further complications in cross-national comparisons.

The first challenge relates to differences in healthcare systems. In England, general practice is the gatekeeper to the health service and the place where the majority of new problems are seen. In other countries, for instance Sweden, direct access to specialty services, such as physiotherapy, is possible. The second challenge relates to the characteristics of data collected in healthcare databases. There may be differences in the extent of data collected (eg, every contact may be recorded in some systems but not in others), and in training and incentives given to healthcare professionals for morbidity recording. Databases may use different coding systems. In primary care in England, morbidities are generally recorded using Read Codes. ${ }^{9}$ The Read Code system is a hierarchical system structured into chapters. Codes under Chapter N represent 'Musculoskeletal and Connective Tissue Diseases'. Elsewhere, including Sweden, morbidities are recorded using International Classification of Disease (ICD-10) codes. The ICD-10 is also hierarchical, Chapter 13 (M) representing 'Diseases of the Musculoskeletal System and Connective Tissue'.

Consultation prevalence of some MSK conditions, ${ }^{8}{ }^{10-12}$ and MSK symptoms by body region, ${ }^{13-16}$ have been presented for localities within nations. However, comparing occurrence of 
MSK conditions presents further challenges, including obtaining valid and comparable case definitions when use of diagnostic labels, such as OA, often varies between healthcare professionals. ${ }^{17} 18$ The inflexibility of coding systems also raise challenges. Although diagnoses have a clear coding system, symptoms such as joint pain and back pain may be spread across several chapters including the MSK, symptoms and injury chapters. $^{13}$

The objectives were, first, to assess the feasibility of comparing the consultation prevalence of MSK conditions between nations with different healthcare and recording systems and, second, to determine the consultation prevalence of specific MSK conditions cross-nationally.

To determine feasibility, we first attempted to harmonise case definitions, data extraction and analysis procedures. Second, prior to analysis, we identified known differences in the healthcare systems and recording practices likely to affect prevalence comparisons. Third, we applied adjustments to the calculation of prevalence where there was a previously established empirical basis for doing so.

\section{METHODS}

\section{Setting}

The study was set within an English and a Swedish healthcare database, two countries with different healthcare and coding systems. The Consultations in Primary Care Archive (CiPCA) contains all recorded consultation data by GPs and practice nurses from 13 general practices in North Staffordshire, England. ${ }^{8} 19$ The practices undergo an annual cycle of assessment, feedback and training in morbidity coding. ${ }^{19}$ Approximately, 97\% of all contacts with a GP have a morbidity code assigned. CiPCA has been shown to give similar annual primary care consultation prevalence figures for MSK conditions, OA, rheumatoid arthritis (RA) and arthralgia as a UK national database. ${ }^{8}$ In England, over 95\% of the population are registered with a general practice, and general practice is the first point of access to the National Health Service for most non-emergency care, and provides continuing care for many chronic diseases. Ethical approval for CiPCA was granted by the North Staffordshire Research Ethics Committee. This study used data from 11 practices which have continuously contributed to CiPCA since 2003. These practices had a total registered population of 94565 in 2010, and cover a range of areas in terms of deprivation, although generally North Staffordshire is more deprived than England as a whole. Although CiPCA is a primary care database, secondary care information (eg, hospital letters) is also recorded and coded at the discretion of the practices. Recording of secondary care information, therefore, will not be complete and will vary by practice.

In Sweden, all healthcare consultations are recorded in county-specific databases. Skåne is the southernmost county. The Skåne Health Care Register (SHCR) holds details for primary and secondary care for 1243329 inhabitants in 2010 (about one-eighth of the Swedish population). In Sweden, all patients are registered to a general practice. However, a patient does not need to attend primary care before seeing a specialist, although this is the most common process. Each consultation generates data entries (eg, diagnostic code) that are transferred to the SHCR and which constitute the basis for reimbursement to the healthcare providers. Similar regulations apply to both public and private healthcare providers, and both are easily accessed. Studies of RA and spondyloarthritis have suggested high validity of diagnostic coding. ${ }^{10} 11$ Approximately $90 \%$ of public primary care consultations and $99 \%$ of secondary care consultations have diagnostic codes recorded in the SHCR. However, diagnostic codes recorded by private outpatient and private primary care providers are not yet automatically transferred to the SHCR. Diagnostic codes recorded by professionals other than doctors are not complete and not included in this analysis. Ethical approval for using data from SHCR for research purposes was given by the Research Ethics Committee at Lund University. The Swedish Population Register is the civil registration of vital events (eg, deaths, change of address). This register can be cross-referenced with the SHCR to determine subjects who have died or relocated out of the county.

\section{Morbidities}

Consultation prevalences based on (1) primary care only and (2) both primary and secondary care were determined in each database for any doctor-diagnosed MSK condition, non-specific low back pain, OA, RA, and spondyloarthritis ( $\mathrm{SpA}$-as a group, and specifically, ankylosing spondylitis (AS), and psoriatic arthritis). In addition, as OA may be recorded as joint pain in the older population, the prevalence of $\mathrm{OA}$ or joint pain was derived for the population aged 45 years and over.

\section{Feasibility criteria}

Assessment of the feasibility of comparing prevalence between England and Sweden was based on two criteria. First, whether the methodology for deriving consultation prevalence could be standardised between the two nations. Feasibility would not be shown if we were unable to translate any part of the methods between the two nations (eg, standardisation between Read and ICD codes). The second criterion was based on two known characteristics of the healthcare systems and recording practices. Direct access to physiotherapy for back pain in Sweden (ie, without referral from a GP) is common but not routinely recorded with a diagnostic code in the SHCR, and there is more complete recording of secondary care in the Swedish than English database. Therefore, the expectation was that there would be a difference between the nations in consultation prevalence of low back pain (higher in England) and of inflammatory disorders when based on primary and secondary care data (higher in Sweden). There should be less marked differences in the prevalence of OA and in primary care prevalence of inflammatory disorders, given evidence that population prevalence of MSK pain (eg, chronic widespread pain) is similar in UK and Sweden. ${ }^{20} 21$

\section{Morbidity definitions}

Based on previous work in Sweden, 10111422 together with discussions within the research team, ICD-10 codes for the morbidities were identified. Low back pain included codes with the terms 'backache' and 'back pain' with no region (lower or upper) stated, as it is presumed the majority of these will be related to low back pain. Primary care consultation prevalence of recorded upper back pain has previously been shown to be only $5 \%$ of that of lower back pain in the English database. ${ }^{13}$ The selected ICD-10 codes were then matched to Read Codes by KJ using a strict mapping of ICD-10 codes to Read Codes. Two research GPs in England also independently matched Read Codes and their linked terms to the definitions for the ICD-10 codes. The GPs did not use the mapping list used by KJ. Disagreements between KJ and the GPs were resolved by consensus.

There were two exceptions to the above process. Codes for joint pain relating to knee, hip, hand/wrist and foot/ankle were previously derived for a separate study in England by a GP research fellow (JE) through (1) a consensus exercise with other 
GPs and (2) assessment of their recorded use in CiPCA. The identified Read Codes were mapped back to ICD-10 codes by AJ with discussions among the research team. A MSK condition was defined as any recorded code within the Musculoskeletal and Connective Tissue Diseases Chapters of the Read Code (England) or ICD-10 (Sweden) systems. See online supplementary table S1 for the definitions used.

\section{Analysis}

Primary care consultation prevalence was defined as the number of patients consulting primary care at least once with the relevant morbidity code recorded during the time period of interest per 10000 registered population.

Two time periods were used:

1. The calendar year 2010 was used to determine annual consultation prevalence with the registered population at 31 December 2010 as the denominator population.

2. The time period 1 January 2004 to 31 December 2010 was used to determine the 7-year period consultation prevalence in the denominator population. Both numerator and denominator were restricted to those who were registered at 31 December 2010. Hence, for chronic diseases this gives an estimate of the point prevalence of the morbidity in the current registered population.

Patients were only counted once for each condition, hence, repeat consultations for the same condition in the time period of interest were ignored. If a patient consulted for more than one of the conditions during that time period, they were included in the numerator for both. Diagnostic codes from private care are not automatically transferred to the SHCR. The proportion of contacts with private primary care doctors is approximately $30 \%$ of all primary care doctor visits and, therefore, the denominator for the Sweden database was reduced by $30 \%$. ${ }^{14}$ This correction was not designed to address the separate issue of direct access to physiotherapy for low back pain in the Swedish healthcare system, which remained a potential source of bias in the two-country comparison.

The analyses were repeated including secondary care data to derive combined primary and secondary care consultation prevalence, on the assumption that some patients may be diagnosed or only consult in secondary care as is particularly likely in Sweden. Since private specialised care is less common than for primary care, the denominator for Sweden for all healthcare was reduced by $15 \%$. The derivation and empirical justification of these adjustments have been presented in earlier papers. $^{10} 1114$

Total and age-gender specific consultation prevalences for each database were determined. There was no restriction by age except for the combined analysis of $\mathrm{OA}$ and joint pain which was calculated for ages 45 years and over. Age was defined as age at 31 December 2010. The age and gender structure of the registered populations for the two databases were similar, hence unstandardised results are presented (table 1).

\section{RESULTS}

\section{Annual consultation prevalence}

There were 2143 persons per 10000 in the English database who had a record of consulting primary or secondary care at least once in the year for a MSK condition. The corresponding figure for Sweden was 1610/10 000 (table 2). This overall difference between England and Sweden was apparent predominantly in the different prevalences for low back pain (587 vs 294/ 10 000). By contrast, RA, SpA and psoriatic arthritis had higher prevalences in the Swedish database, although OA (211 vs 269/
Table 1 Registered populations at 31 December 2010

\begin{tabular}{lcc}
\hline Age & CiPCA; $\boldsymbol{n}(\%)$ & SHCR; $\mathbf{n}(\%)$ \\
\hline Women & & \\
$0-14$ & $7427(8)$ & $100927(8)$ \\
$15-24$ & $5511(6)$ & $81931(7)$ \\
$25-44$ & $12283(13)$ & $163828(13)$ \\
$45-64$ & $12786(14)$ & $154292(12)$ \\
$65-74$ & $4999(5)$ & $62552(5)$ \\
$75+$ & $5061(5)$ & $63804(5)$ \\
Men & & \\
$0-14$ & $7738(8)$ & $106707(9)$ \\
$15-24$ & $5613(6)$ & $83271(7)$ \\
$25-44$ & $12553(13)$ & $169078(14)$ \\
$45-64$ & $12761(13)$ & $155032(12)$ \\
$65-74$ & $4603(5)$ & $59787(5)$ \\
$75+$ & $3230(3)$ & $42120(3)$ \\
Total & 94565 & 1243329 \\
\hline CiPCA, Consultations in Primary Care Archive; SHCR, Skåne Health Care Register.
\end{tabular}

10000 ) and AS (5 vs 6/10 000) prevalence figures were similar between the two nations.

When the analysis was restricted to primary care consultations only, the absolute difference in prevalence of MSK consultation was little changed (1967/10 000 England vs 1354/10 000 Sweden), and was again mainly apparent in consultations for low back pain. OA (176 vs 196/10 000), RA (25 vs 26/10 000), SpA (both 8/10 000) and psoriatic arthritis (5 vs 3/10 000) primary care consultation prevalences were similar between the two countries. AS was rarely recorded in Swedish primary care.

\section{Seven-year period consultation prevalence}

Similar cross-national patterns to the annual consultation prevalence figures were observed when assessing 7-year period consultation prevalence (table 3). These figures suggest around 700/ 10000 received a diagnosis of OA over the 7-year period,

Table 2 Annual consultation prevalence $(95 \% \mathrm{Cl})$ per 10000 registered population in 2010 (all ages)

\begin{tabular}{|c|c|c|}
\hline & $\begin{array}{l}\text { North Staffordshire, } \\
\text { England }\end{array}$ & $\begin{array}{l}\text { Skåne County, } \\
\text { Sweden }\end{array}$ \\
\hline \multicolumn{3}{|l|}{ Primary and secondary care } \\
\hline Musculoskeletal (all) & 2143 (2114 to 2173 ) & 1610 (1603 to 1617$)$ \\
\hline Low back pain & 587 (572 to 603) & 294 (290 to 297) \\
\hline Rheumatoid arthritis & 40 (36 to 44$)$ & 59 (58 to 61$)$ \\
\hline Spondyloarthritis* & 13 (11 to 16$)$ & 30 (29 to 31$)$ \\
\hline Ankylosing spondylitis & 5 (3 to 6$)$ & 6 (5 to 6$)$ \\
\hline Psoriatic arthritis & $8(6$ to 10$)$ & 16 (15 to 17$)$ \\
\hline Osteoarthritis & 211 (202 to 220 ) & 269 (266 to 272 ) \\
\hline \multicolumn{3}{|l|}{ Primary care only } \\
\hline Musculoskeletal (all) & 1967 (1939 to 1995) & 1354 (1347 to 1361$)$ \\
\hline Low back pain & 543 (529 to 558 ) & 290 (286 to 293 ) \\
\hline Rheumatoid arthritis & 25 (22 to 28$)$ & 26 (25 to 28$)$ \\
\hline Spondyloarthritis* & $8(7$ to 10$)$ & 8 (8 to 9 ) \\
\hline Ankylosing spondylitis & 3 (2 to 4$)$ & $0.2(0.1$ to 0.3$)$ \\
\hline Psoriatic arthritis & 5 (3 to 6$)$ & 3 (3 to 4 ) \\
\hline Osteoarthritis & 176 (168 to 185$)$ & 196 (193 to 199) \\
\hline
\end{tabular}

${ }^{*}$ Ankylosing spondylitis, psoriatic arthritis, arthropathy in ulcerative colitis, arthropathy in Crohn's disease. 
Table 3 Seven-year period consultation prevalence of musculoskeletal conditions* $(95 \% \mathrm{Cl})$ per 10000 registered population (all ages)

\begin{tabular}{|c|c|c|}
\hline & $\begin{array}{l}\text { North Staffordshire, } \\
\text { England }\end{array}$ & $\begin{array}{l}\text { Skåne County, } \\
\text { Sweden }\end{array}$ \\
\hline \multicolumn{3}{|l|}{ Primary and secondary care } \\
\hline Musculoskeletal (all) & 5055 (5010 to 5101 ) & 4278 (4269 to 4288 ) \\
\hline Low back pain & 2113 (2083 to 2142) & 1093 (1087 to 1099$)$ \\
\hline Rheumatoid arthritis & 57 (52 to 62$)$ & 90 (89 to 92$)$ \\
\hline Spondyloarthritist & 28 (25 to 31$)$ & 62 (60 to 63$)$ \\
\hline Ankylosing spondylitis & 10 (8 to 12$)$ & 13 (13 to 14$)$ \\
\hline Psoriatic arthritis & 13 (11 to 15$)$ & 30 (29 to 31$)$ \\
\hline Osteoarthritis & 651 (635 to 667$)$ & 733 (728 to 738 ) \\
\hline \multicolumn{3}{|l|}{ Primary care only } \\
\hline Musculoskeletal (all) & 4914 (4869 to 4959) & 3895 (3885 to 3905 ) \\
\hline Low back pain & 2053 (2024 to 2082) & 1077 (1070 to 1083$)$ \\
\hline Rheumatoid arthritis & 48 (43 to 52$)$ & 52 (51 to 54$)$ \\
\hline Spondyloarthritis† & 23 (20 to 27 ) & 21 (20 to 22 ) \\
\hline Ankylosing spondylitis & $8(6$ to 10$)$ & $0.4(0.3$ to 0.6$)$ \\
\hline Psoriatic arthritis & 10 (8 to 13$)$ & 8 (7 to 8$)$ \\
\hline Osteoarthritis & 586 (571 to 602 ) & 493 (489 to 498 ) \\
\hline
\end{tabular}

between 57 (England) and 90 (Sweden) per 10000 received a diagnosis of RA, and 10-13/10 000 received a diagnosis of AS.

\section{$O A$ and joint pain}

The consultation prevalence of diagnosed OA in those aged 45 years and over was reasonably consistent between England and Sweden at around 500/10 000 (annual) and 1400-1500/10 000 (7-year period consultation prevalence) (table 4). Including joint pain codes with OA increased these figures to around 1100/

Table 4 Consultation prevalence of osteoarthritis and joint pain* $(95 \% \mathrm{Cl})$ per 10000 registered population aged 45 years and over

North Staffordshire, Skåne County, England Sweden

\begin{tabular}{|c|c|c|}
\hline \multicolumn{3}{|c|}{ Annual consultation prevalence 2010} \\
\hline \multicolumn{3}{|l|}{ Primary and secondary care } \\
\hline Osteoarthritis & 447 (428 to 468$)$ & 578 (571 to 585$)$ \\
\hline Joint pain & 875 (847 to 903$)$ & 631 (624 to 638) \\
\hline Osteoarthritis or joint pain & 1192 (1160 to 1225$)$ & 1094 (1085 to 1103$)$ \\
\hline \multicolumn{3}{|l|}{ Primary care only } \\
\hline Osteoarthritis & 375 (357 to 393 ) & 443 (436 to 449$)$ \\
\hline Joint pain & 794 (768 to 821$)$ & $603(596$ to 610$)$ \\
\hline Osteoarthritis or joint pain & 1074 (1044 to 1106$)$ & 967 (958 to 977) \\
\hline \multicolumn{3}{|c|}{ Seven-year period consultation prevalencet } \\
\hline \multicolumn{3}{|l|}{ Primary and secondary care } \\
\hline Osteoarthritis & 1388 (1353 to 1423$)$ & 1563 (1553 to 1574$)$ \\
\hline Joint pain & 2942 (2892 to 2994) & 2459 (2445 to 2472$)$ \\
\hline Osteoarthritis or joint pain & 3483 (3428 to 3539 ) & 3346 (3332 to 3360$)$ \\
\hline \multicolumn{3}{|l|}{ Primary care only } \\
\hline Osteoarthritis & 1254 (1221 to 1288$)$ & 1111 (1101 to 1121$)$ \\
\hline Joint pain & 2847 (2797 to 2898 ) & 2511 (2498 to 2524$)$ \\
\hline Osteoarthritis or joint pain & 3363 (3308 to 3418$)$ & 3075 (3060 to 3089) \\
\hline
\end{tabular}

${ }^{*}$ People had to be aged 45 years or over when receiving joint pain code.

tAny record of morbidity between 2004 and 2010.
10000 (annual) and 3400/10 000 (7-year period consultation prevalence) although recorded joint pain prevalence was slightly higher for England.

\section{Age-gender patterns}

Age-gender patterns were generally similar between England and Sweden (figures 1 and 2). There was a more evident plateau in low back pain prevalence at the older ages in England, while the higher prevalence of RA for women was more marked in Sweden.

\section{Sensitivity analysis}

To correct for missing codes from private doctors, we adjusted the denominator for Swedish consultation prevalence by 30\% for primary care and $15 \%$ when including secondary care. Sensitivity analyses using a $25 \%$ or $35 \%$ adjustment for primary care changes the annual consultation prevalence figures for RA from 26/10 000 to $25 / 10000$ and $28 / 10000$, respectively. For SpA, consultation prevalence remained at $8 / 10000$ with $25 \%$ adjustment and increased to $9 / 10000$ with $35 \%$ adjustment. Estimated low back pain annual consultation prevalence reduced from 290 to $270 /$ 10000 with $25 \%$ adjustment, and increased to $312 / 10000$ with $35 \%$ adjustment. For OA, the prevalence changed from 196/ 10000 to $183 / 10000$ and 211/10 000, respectively.

\section{DISCUSSION}

Comparisons of routine healthcare data between countries and healthcare systems allow opportunities to study causes and differences in management and outcome of morbidities. All databases using routine morbidity coding will incorporate variation by clinicians in diagnostic criteria and in recording of morbidities, potentially leading to variation in recorded prevalence. Between countries, such variations may be exacerbated by differences in coding systems and contrasting components of the healthcare systems which may affect how morbidity data is recorded and collected. There may also be underlying differences in the occurrence of different conditions between countries and in the delivery and effectiveness of healthcare, contributing to observed differences in prevalence figures.

However, it appears feasible to compare consultation prevalence between nations by using a rigorous approach to data organisation and extraction. The approach we used included the matching of Read Codes to ICD-10 codes through structured consensus processes of researchers and clinicians, prior to extraction of consultations, suggesting the two coding systems can be mapped to allow comparisons between international healthcare systems. We observed some consistency in consultation prevalence of MSK conditions between English and Swedish databases despite their dissimilar healthcare systems and recording practices. The contrasts we observed were expected and may be partially explained by two known differences. First, direct access to some primary care in Sweden, for instance, physiotherapy for back pain, is not routinely recorded in the SHCR. Second is the direct transfer of secondary care data to the SHCR in Sweden.

Consultation prevalence of low back pain in Sweden was only half of that found in England and may be a result of patients in Sweden having direct access to physiotherapists whose diagnostic codes are not comprehensively recorded in the SHCR. Patients who directly access physiotherapy tend to be younger, more educated and more likely to have unspecified symptoms, ${ }^{23} 24$ and approximately $70 \%$ of low back pain patients have their initial contact with a physiotherapist (unpublished data). Differences between the nations in consultation prevalence for inflammatory conditions using both primary and 
Figure 1 Annual (2010) consultation prevalence of musculoskeletal conditions by age and sex. All care includes primary and secondary care. LBP, low back pain; MSK, musculoskeletal; OA, osteoarthritis; PC, primary care; $R A$, rheumatoid arthritis; SpA, spondyloarthritis.
Women
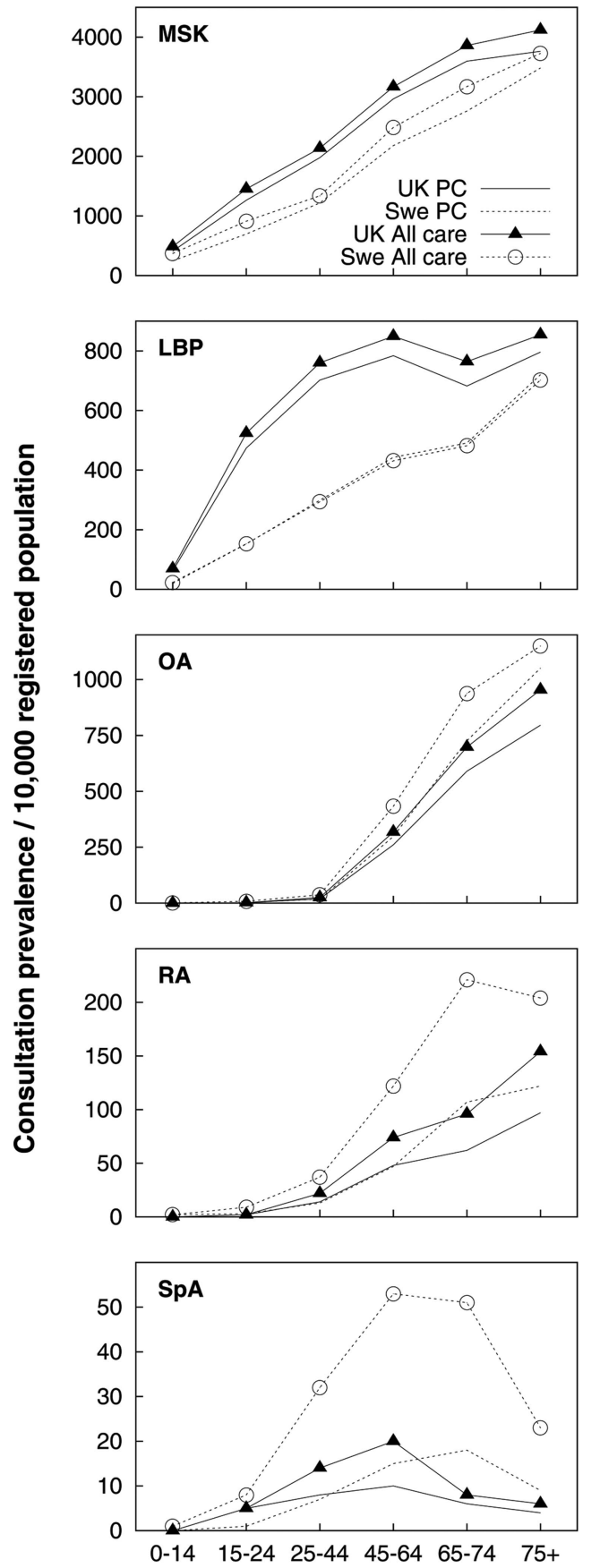

Men
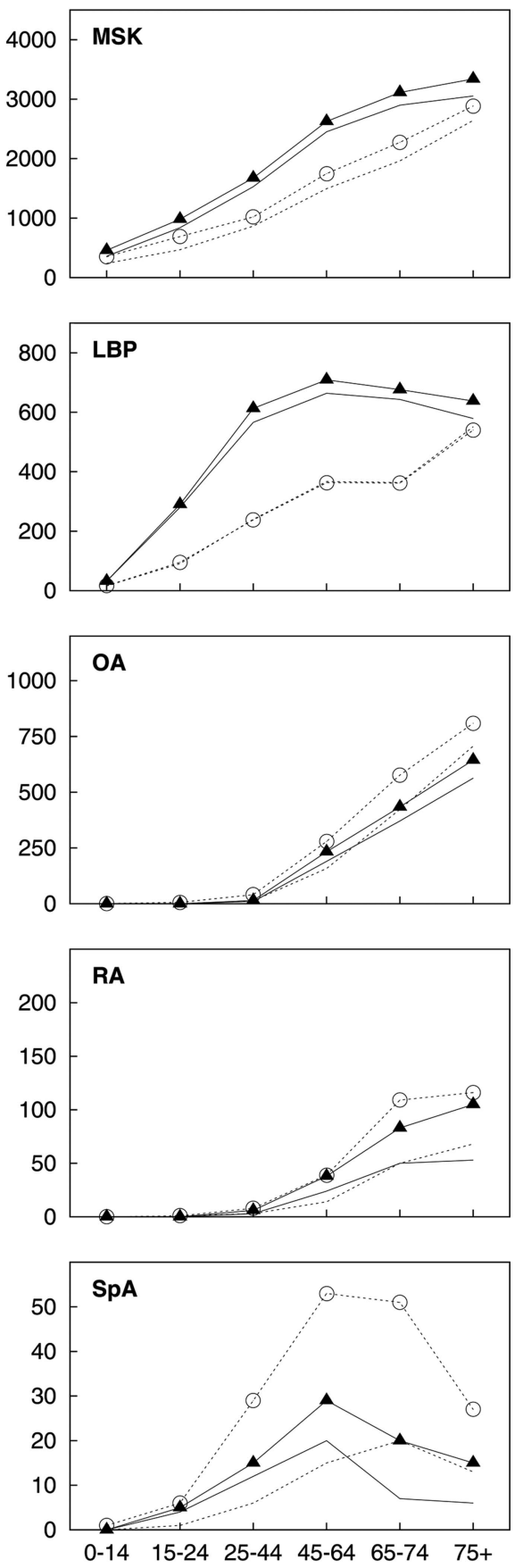

Age groups

secondary care data may reflect the nature of the conditions in being diagnosed and seen more commonly in secondary care, as suggested by the increased prevalence when secondary care is considered in the SHCR database. Although English general practices, such as those included in CiPCA, do not comprehensively record diagnoses made in secondary care, it might be expected that a person with a diagnosis in secondary care would obtain a record of this at least once over 7 years. However, the combined primary and secondary care figures for England are likely to be an underestimate of consultation prevalence for the inflammatory conditions, and the true prevalence is likely to be closer to the figures derived for Sweden.
One challenge in comparing consultation prevalence figures is in deciding on what constitutes 'similar' prevalence. Consideration of absolute differences may prove the best approach to comparing consultation prevalence. For example, Swedish annual primary and secondary care prevalence of psoriatic arthritis is twice that for England, but the absolute difference is low (eight extra people consulting per 10000 ), whereas for a more prevalent condition like low back pain, a similar relative ratio constitutes a larger absolute difference (293 extra people consulting in England per 10 000).

The prevalence figures reflect the burden of MSK conditions with $15-20 \%$ of people seeking care for a MSK problem during 
Figure 2 Seven year (2004-2010) period consultation prevalence of musculoskeletal conditions by age and sex. (LBP, low back pain; MSK, musculoskeletal; $\mathrm{OA}$, osteoarthritis; $\mathrm{PC}$, primary care; $R A$, rheumatoid arthritis; SpA, spondyloarthritis).
Women
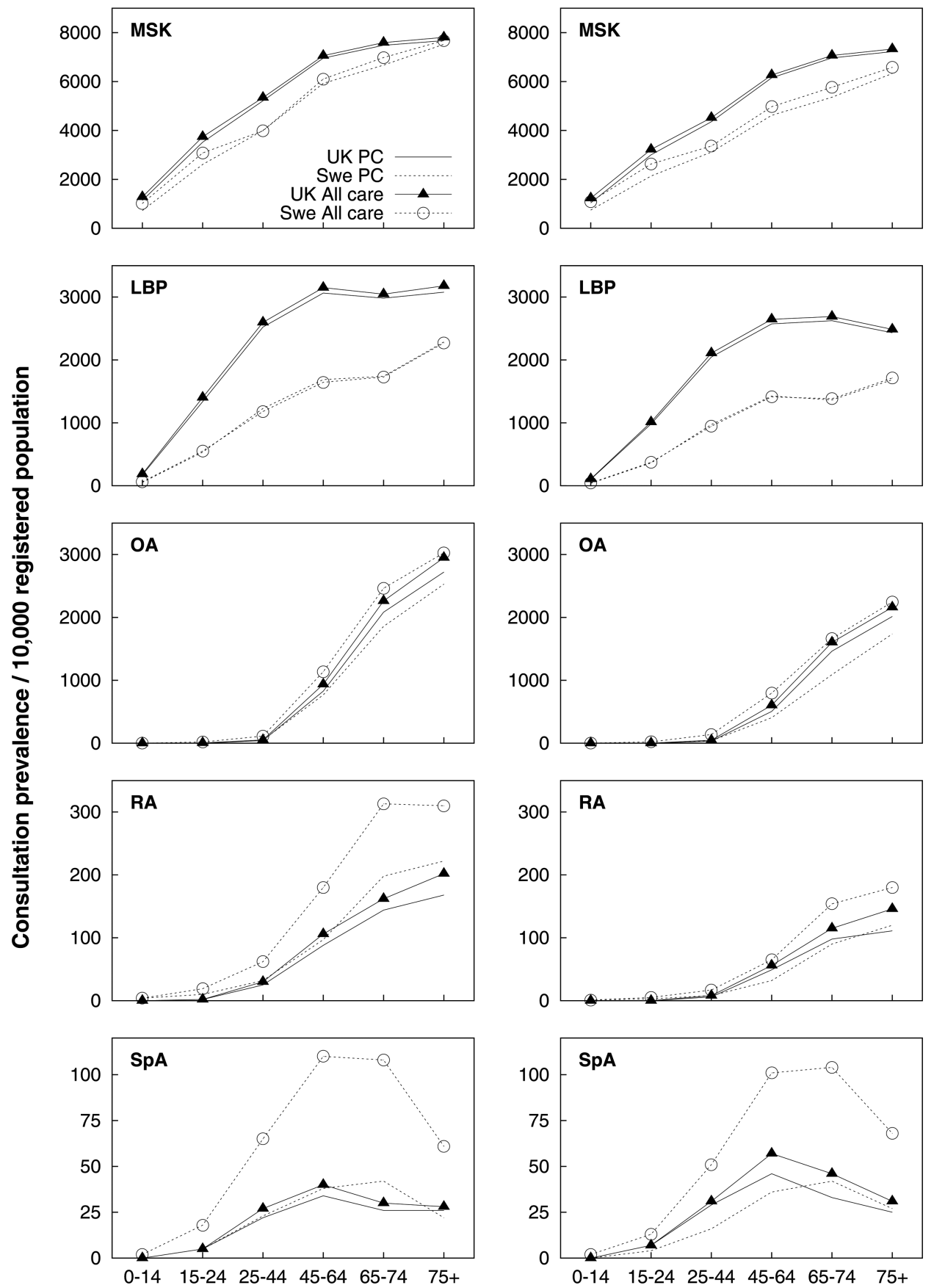

Age groups the course of a year, rising to 50\% (5055/10 000 England; $4278 / 10000$ Sweden) over the course of 7 years. Low back pain and $\mathrm{OA}$ are common with a third of older adults consulting for OA or joint pain over a 7-year period.

The annual primary care consultation prevalence figures for all MSK conditions, OA and RA are similar to the last published figures (for year 2007) from the national Research and Surveillance Centre across England and Wales (all MSK 1692/ 10 000; OA 188/10 000; RA: 30/10 000). ${ }^{25}$ The 7 year combined primary and secondary care period consultation prevalence figures for OA are not dissimilar to those identified in British Columbia, Canada, for the period 1994-2001 (approximately 900/10 000), although that study showed that increasing the period from seven to 10 years increased the consultation prevalence of diagnosed OA in the current registered population by about $20 \% .^{12}$ Therefore, the 7 -year figures given here may be a slight underestimate of the actual current prevalences of the chronic diseases investigated, although those without a healthcare record for more than 7 years would probably have milder symptoms.

Diagnostic codes from private care are not automatically transferred to the SHCR. Both private and public care in Sweden are easily accessed with the same patient cost. Selection bias between private and public care is possible, but due to the nature of the Swedish healthcare system, unlikely to be substantial. In $2010,69 \%$ of all patients consulting privately were aged 
20-69 years, compared with 58\% for public care. The consultation prevalence figures for working-age individuals from Sweden may hence be slightly underestimated.

We based our prevalence figures on the underlying diagnosis favoured by the doctor at time of recording. Validation data for RA and SpA from SHCR support high accuracy of the diagnostic coding. ${ }^{10} 11$ CiPCA covers one area of England but has been shown to give comparable prevalence figures to national databases. ${ }^{8}$ People registering at the CiPCA practices or moving into Skåne after the start of 2004 will not have a full 7 years of medical record information. This is likely to be a bigger proportion of the registered population of the more local CiPCA database than SHCR. Repeating the 7-year prevalence analysis in CiPCA for just those fully registered between 2004 and 2010 increased consultation prevalence from 651 to $758 / 10000$ but only increased prevalence of RA by $10 \%$ and less for the other conditions. We assumed that a code of backache or back pain, without lower or upper region specified, would most likely refer to low back pain, given the low prevalence of upper back pain. ${ }^{13}$ However, it is possible that some individuals with only upper back pain may have been included.

Our study suggests that use of a rigorous methodological approach allows feasible comparison between England and Sweden and some consistency in consultation prevalence figures despite differences in healthcare and recording systems. Differences observed will represent contrasts in diagnosis, coding or healthcare referral practice in the two countries, but may also include real variations in prevalence. As deeper understanding is gained about healthcare data in different countries, so these different possibilities can be explored. Further research should, therefore, examine whether consistency can be found between other European and non-European countries.

Acknowledgements The Keele GP Research Partnership and the Informatics team at the Arthritis Research UK Primary Care Centre. John Bedson and Richard Hayward for help in deriving the appropriate Read Codes. The staff at the Epi-centre Skåne, Lund, Sweden.

Contributors KJ, AJ, CB, PC, GP, IP, RW and ME designed the study. KJ, AJ, CB, $A T$ and JE ensured morbidity definition and data extraction was harmonised between the two nations. $\mathrm{KJ}$ and $\mathrm{AJ}$ performed the analysis. All authors contributed to the interpretation of the analysis. $\mathrm{KJ}, \mathrm{AJ}$ and $\mathrm{ME}$ led the writing of the paper. All authors critically revised it and approved the final manuscript.

Funding CiPCA funded by the North Staffordshire Primary Care Research Consortium and Keele University Institute for Primary Care and Health Sciences. Analysis of SHCR funded by grants from the regional health service authorities of Skåne County (Region Skåne), The Swedish Research Council, The Kock Foundation, Gustav V's 80-year Birthday Foundation, Maggie Stephens Foundation, and the Medical Faculty, Lund University, Sweden.

\section{Competing interests None.}

Ethics approval North Staffordshire Local Research Ethics Committee and Lund University Research Ethics Committee.

Provenance and peer review Not commissioned; externally peer reviewed.

Open Access This is an Open Access article distributed in accordance with the Creative Commons Attribution Non Commercial (CC BY-NC 3.0) license, which permits others to distribute, remix, adapt, build upon this work non-commercially, and license their derivative works on different terms, provided the original work is properly cited and the use is non-commercial. See: http://creativecommons.org/ licenses/by-nc/3.0/

\section{REFERENCES}

1 Croft $P$, Blyth FM, van der Windt D. The global occurrence of chronic pain: an introduction. In: Croft P, Blyth FM, van der Windt D, eds. Chronic pain epidemiology. From aetiology to public health. Oxford: Oxford University Press, 2010: 9-18.

2 Gureje 0 , Von Korff M, Simon GE, et al. Persistent pain and well-being: a World Health Organization Study in Primary Care. JAMA 1998;280:147-51.

3 Mäntyselkä P, Kumpusalo $E$, Ahonen $R$, et al. Pain as a reason to visit the doctor: a study in Finnish primary health care. Pain 2001:89:175-80.

4 Hasselström J, Liu-Palmgren J, Rasjö-Wrååk G. Prevalence of pain in general practice. Eur J Pain 2002;6:375-85.

5 WHO Scientific Group on the Burden of Musculoskeletal Conditions at the Start of the New Millennium. The burden of musculoskeletal conditions at the start of the new millennium. World Health Organ Tech Rep Ser 2003;919:1-218.

6 Perry DC, Machin DM, Pope D, et al. Racial and geographic factors in the incidence of Legg-Calvé-Perthes' disease: a systematic review. Am J Epidemiol 2012;175:159-66.

7 van den Dungen $\mathrm{C}$, Hoeymans $\mathrm{N}$, Boshuizen $\mathrm{H}$, et al. The influence of population characteristics on variation in general practice based morbidity estimations. BMC Public Health 2011;11:887.

8 Jordan K, Clarke AM, Symmons DP, et al. Measuring disease prevalence: a comparison of musculoskeletal disease using four general practice consultation databases. Br J Gen Pract 2007:57:7-14.

9 NHS Information Authority. The Clinical Terms Version 3 (The Read Codes). Birmingham: NHS Information Authority, 2000.

10 Englund $M$, Jöud $A$, Geborek $P$, et al. Prevalence and incidence of rheumatoid arthritis in southern Sweden 2008 and their relation to prescribed biologics. Rheumatology (Oxford) 2010;49:1563-9.

11 Haglund $E$, Bremander $A B$, Petersson IF, et al. Prevalence of spondyloarthritis and its subtypes in southern Sweden. Ann Rheum Dis 2011;70:943-8.

12 Kopec JA, Rahman MM, Berthelot J-M, et al. Descriptive epidemiology of osteoarthritis in British Columbia, Canada. J Rheumatol 2007;34:386-93.

13 Jordan KP, Kadam UT, Hayward R, et al. Annual consultation prevalence of regional musculoskeletal problems in primary care: an observational study. $B M C$ Musculoskelet Disord 2010;11:144.

14 Jöud A, Petersson IF, Englund M. Low back pain-epidemiology of consultations. Arthritis Care Res (Hoboken) 2012;64:1084-8.

15 Linsell L, Dawson J, Zondervan K, et al. Prevalence and incidence of adults consulting for shoulder conditions in UK primary care; patterns of diagnosis and referral. Rheumatology (Oxford) 2006:45:215-21.

16 van der Waal JM, Bot SD, Terwee $C B$, et al. The incidences of and consultation rate for lower extremity complaints in general practice. Ann Rheum Dis 2006;65:809-15.

17 Lacoucere M, Rahme E, Pineau CA, et al. Robustness of prevalence estimates derived from misclassified data from administrative databases. Biometrics 2007;63:272-9

18 Bierma-Zeinstra SM, Lipschart S, Njoo KH, et al. How do general practitioners manage hip problems in adults? Scand J Prim Health Care 2000;18:159-64.

19 Porcheret $M$, Hughes $R$, Evans $D$, et al. Data quality of general practice electronic health records: the impact of a program of assessments, feedback, and training. J Am Med Inform Assoc 2004;11:78-86.

20 Bergman S, Herrström P, Högström K, et al. Chronic musculoskeletal pain, prevalence rates, and sociodemographic associations in a Swedish population study. J Rheumatol 2001;28:1369-77.

21 Papageorgiou AC, Silman AJ, Macfarlane GJ. Chronic widespread pain in the population: a seven year follow up study. Ann Rheum Dis 2002:61:1071-4.

22 Turkiewicz A, Petersson IP, Björk J, et al. Consultation prevalence of osteoarthritis in southern Sweden [abstract]. Arthritis Rheum 2012;64(Suppl):S396-7.

23 Holdsworth LK, Webster VS, McFadye AK. Are patients who refer themselves to physiotherapy different from those referred by GPs? Results from national trial. Physiotherapy 2006;92:26-33.

24 Leemrijse CJ, Swinkels IC, Veenhof C. Direct access to physical therapy in the Netherlands: results from the first year in community-based physical therapy. Phys Ther 2008;88:936-46.

25 RCGP Birmingham Research Unit Weekly Returns Service Annual Prevalence Report 2007. Birmingham. 2007. 